\title{
Patients' Survival Expectations Before Localized Prostate Cancer Treatment by Treatment Status
}

\author{
Ravinder Mohan, Hind Beydoun, Myra L. Barnes-Ely, \\ LaShonda Lee, John W. Davis, Raymond Lance and Paul Schellhammer \\ Department of Family and Community Medicine, \\ Eastern Virginia Medical School, Norfolk, Virginia,
} USA

\section{Introduction}

Although around $80 \%$ of men aged 80 years and older and $15 \%$ to $30 \%$ of men aged 50 years and older have microscopic undiagnosed prostate cancer found at autopsy, only 3\% men die because of prostate cancer. ${ }^{1}$ Increasing prostate-specific antigen (PSA) screening at younger ages has increased overdiagnosis ${ }^{2}$ and overtreatment ${ }^{3}$ of localized prostate cancer (LPC). More than $90 \%$ of US patients currently diagnosed with prostate cancer have LPC and approximately $94 \%$ of patients with LPC choose treatment. ${ }^{4}$ Based on data from leading studies, a model had recently projected only a $0 \%$ to $2 \% 15$-year mortality from low-grade (Gleason score $<7$ ) screen-detected LPC in men aged 55 to 74 years if they chose observation instead oftreatment. ${ }^{5}$ By consensus, urologists and radiation oncologists recommend treatment for LPC if a patient has a further 10-year life expectancy ${ }^{6}$ (the10-year rule 7 ) regardless of cancer grade, even though no randomized trials have shown that treatment can improve survival in patients in whom the cancer was screen-detected. National guidelines by the American Cancer Society and the National Comprehensive Cancer Network (NCCN) also recommend treatment for most patients. ${ }^{8}$ However, in the review by Zeliadt et al, ${ }^{9}$ different studies had found that patients rate the sexual, urinary, and bowel side effects of treatment to be just as important as the potential benefit in survival; that if risks and benefits of treatment were explained with-out bias, $75 \%$ of patients chose a lower radiation dose despite a lower predicted survival; that $90 \%$ of physicians but fewer than $20 \%$ of patients ranked the effect of treatment on survival as one of their top 4 concerns; and that patients who chose treatment believed that treatment was guaranteed to improve survival. At a median of 6 years after treatment, health-related quality of life (HRQOL) of treated patients was worse than that of controlpatients. ${ }^{10}$ Many patients regretted that they chosetreatment. ${ }^{11}$

To our knowledge, no studies of patient-physician communication have examined patients' anticipated survival benefit of treatment. Without data from randomized trials in screendetected patients, it is difficult to counsel patients regarding their survival with and without treatment. Even with the use of multi-factorial models, accuracy of predicted survival is $75 \%$ or lower. ${ }^{12}$ Physicians are also poor at estimating baseline co-morbidity adjusted life expectancy (CALE), which is critical in making an informed decision. ${ }^{13}$ Thus, patients may 
accept a treatment recommendation not knowing what their baseline CALE is, how much the newly diagnosed cancer could reduce it, or how effectively treatment could minimize that reduction. Current over-treatment of LPC might be because patients do not understand the pros and cons of treatment.

In this study we surveyed newly diagnosed patients about their anticipation of survival with and without treatment. By estimating their baseline CALE without considering the newly diagnosed cancer, we calculated their perceived decrease in longevity with observation (PDLO), and their perceived increase in longevity with treatment (PILT) for the cancer.

\section{Methods}

We surveyed patients who had been newly diagnosed with LPC (stages T1a to T2c) in the preceding 6 months, had met with their urologist after the diagnosis, were scheduled to receive treatment or observation, and had not yet been treated with surgery or radiation. Patients with dementia, or those who could not read, write, or understand English, were excluded. All patients were recruited from a large, private urology practice in Norfolk, Virginia. Staff at this practice systematically contacted patients newly diagnosed with LPC between March 2005 and November 2007 regarding their interest in participation in a selfadministered mailed survey. Two concomitant pretreatment self-administered surveys were used. The first survey asked patients about expectations of survival with and without treatment, co-morbid diseases, mood, social support, satisfaction with life, health, and education by physicians about treatment options. A list of health-related words in a closed envelope was mailed with the survey. Patients were requested to open the envelope and read these words on the telephone to a research assistant. This was done to estimate patient health literacy by using a brief version of the Rapid Estimation of Health Literacy in Medicine scale.14 Patients were given a $\$ 10$ stipend for completing this survey. A second pretreatment survey was a part of a longitudinal follow-up by urologists to evaluate generic HRQOL, prostate cancer related symptoms, and fear of cancer recurrence. The study methods were reviewed and approved by an Institutional Review Board.

\section{Measures}

The Charlson Comorbidity Index (CCI) is a validated measure of co-morbidity. We used a patient self-reported CCI scale that asked about the presence and severity of 12 chronic conditions; the Prostate Cancer Outcomes Study used this CCI version. ${ }^{15}$ Score categories are $0,1,2$, and 3 or more diseases.

The NCCN practice guidelines had recommended, for the first time in 2007,8 that the health adjusted life expectancy of LPC patients can be estimated by weighting age-based life expectancy by 1.5 for patients in the highest health quartile, using no weighting for patients in the middle 2 health quartiles, and weighting by 0.5 for patients in the lowest health quartile. We used co-morbidity scores as surrogate markers of health status because comorbidity is the main determinant of life expectancy in older patients, 16 and the most important prognostic factor for patients with LPC who are $<75$ years old is the co-morbidity score. ${ }^{17}$ We categorized patients into health quartiles by using their CCI score ( 0 disease score $=$ highest health quartile; 1 or 2 disease score $=$ middle 2 health quartiles; 3 or higher disease score $=$ lowest health quartile). Our basis of equating a 1 or 2 disease score with the middle 2 health quartiles was that almost half (49\%) of the 3173 patients newly diagnosed 
with LPC in a Prostate Cancer Outcomes Study15 had a disease score of 1 or 2, and almost half $(55.5 \%)$ of our patients had a disease score of 1 or 2 . Both studies used the same version and scoring of the CCI. Patients were placed in 4 CALE categories: $<5$ years, 5 to 10 years, 10 to 20 years, and 20 years. These 4 categories were scored, respectively, from 1 to 4 .

Patients were asked the following 2 questions: "How long do you expect you will live without any treatment for prostate cancer?" (Q1) and "How long do you expect you will live after treatment for prostate cancer?" (Q2). The possible responses to both questions were grouped into 4 categories (similar to the CALE categories): $<5$ years, 5 to 10 years, 10 to 20 years, and $>20$ years. These 4 categories were also scored from 1 to 4 , respectively. Based on Q1, Q2, and CALE scores, we calculated the patient's PDLO (which is CALE category score minus Q1 category score) and the patient's PILT (which is Q2 category score minus Q1 category score). A PDLO of 10 or more years is at least a 2-category difference between the CALE category and the Q1 category; this is only possible if the CALE was $>20$ years and the Q1 response was 5 to 10 years or if the CALE was 10 to 20 years and the Q1 response was $<5$ years. Similarly, a PILT of 10 or more years indicates that the response to Q2 was 10 years or more than the response to Q1. We conducted ordinal logistic regression analyses to identify the main socio-demographic, health, and cancer characteristics that could predict PDLO and PILT of 10 or more years.

The following validated self-administered scales were used. (1) The Short-Form 36 (SF-36, version 2) measures generic HRQOL; we calculated physical component summary and mental component summary scores from SF-36 data. ${ }^{18}$ (2) The Prostate Cancer Index measures urinary, sexual, and bowel symptoms and how much they bother the patient. ${ }^{19}$ (3) The Duke Activity Status Index ${ }^{20}$ measures functional capacity in metabolic equivalents; this scale asks patients whether they could perform 12 activities which have different levels of exertion. (4) The Hospital Anxiety and Depression Scale measures the presence and severity of anxiety and depression. ${ }^{21}$ (5) The Fear of Cancer Recurrence Scale measures the fear of possible cancer recurrence.22 (6) The Medical Outcomes Study Social Support Survey measures social support in an overall score that includes multidimensional sub-scores. ${ }^{23}(7)$ The Delighted-Terrible Seven Faces Scale ${ }^{24}$ was used to measure patient satisfaction with life, health, and with education given by physicians about treatment options for LPC. (8) The Rapid Estimation of Health Literacy in Medicine scale, discussed earlier, measures health literacy; this was the only scale administered by telephone. ${ }^{14}$

\section{Statistical analyses}

Frequencies and relative frequencies were used to describe categorical variables. Continuous variables were described using the mean, median, and SD. Chi-square tests, Fisher's exact test, and independent sample $t$ tests were used to examine bivariate associations. Unadjusted and adjusted odds ratios (ORs) and their 95\% CIs were estimated using ordinal logistic regression analysis. Socio-demographic and health factors that were found to be associated with PDLO and PILT in the bivariate analysis at an alpha level of 0.20 were kept in the multivariate models. All analyses were performed using SAS software (version 9.1, SAS Institute, Inc., Cary, NC).

\section{Results}

Surveys were mailed to 430 patients newly diagnosed with LPC, but 69 patients had already started treatment by the time the patients received the surveys, 3 patients never received the 
surveys, and 2 patients were found to be ineligible to participate because their cancer was not localized to the prostate. Of the 356 remaining patients, 104 patients did not return the survey because they were "not interested" in participating and 68 patients who did not return the surveys did not give a reason for not participating or could not be contacted. One hundred eighty-four of 356 patients (survey response rate of 52\%) completed and returned the first pretreatment survey; 23 of these 184 patients (12.5\%) patients chose observation. Table 1 shows a demographic comparison of patients who chose treatment or observation. Mean patient age was 61.5 years, and most patients reported college education and a family income of $>\$ 50,000$.

\begin{tabular}{|c|c|c|c|c|}
\hline \multicolumn{2}{|l|}{ Overall } & \multirow{2}{*}{$\begin{array}{c}\text { Treatment } \\
\text { (n [\%]) }\end{array}$} & \multicolumn{2}{|c|}{ Observation } \\
\hline Characteristic & (n [\%]) & & $(\mathrm{n}[\%])$ & $\mathrm{P} \ddagger$ \\
\hline Age (years) & $\mathrm{n}=184$ & $\mathrm{n}=161$ & $\mathrm{n}=23$ & \\
\hline$<60$ & $71(38.6)$ & $68(42.2)$ & $3(13.0)$ & \\
\hline $60-70$ & $91(49.5)$ & $81(50.3)$ & $10(43.5)$ & \\
\hline$>70$ & $22(11.9)$ & $12(7.5)$ & $10(43.5)$ & $<.0001$ \\
\hline Mean +/-SD & $61.5+/-7.9$ & $60.6+/-7.6$ & $68.2+/-5.9$ & $<.0001$ \\
\hline Race & $\mathrm{n}=184$ & $\mathrm{n}=161$ & $n=23$ & \\
\hline African American & $26(14.1)$ & $26(16.2)$ & $0(0.0)$ & \\
\hline White & $158(85.9)$ & 135 (83.9) & $23(100)$ & $.05 \S$ \\
\hline Education & $\mathrm{n}=180$ & $\mathrm{n}=157$ & $\mathrm{n}=23$ & \\
\hline$<$ High school & $7(3.9)$ & $7(4.5)$ & $0(0.0)$ & \\
\hline High school & $65(36.1)$ & $56(35.7)$ & $9(39.1)$ & \\
\hline College & $108(60.0)$ & $94(59.9)$ & $14(60.9)$ & .58 \\
\hline Health literacy & $\mathrm{n}=173$ & $\mathrm{n}=150$ & $\mathrm{n}=23$ & \\
\hline Below 6th grade & $1(0.6)$ & $1(0.7)$ & $0(0.0)$ & \\
\hline 6th-9th grade & $16(9.3)$ & $15(10.0)$ & $1(4.4)$ & \\
\hline$>9$ th grade & $156(90.2)$ & $134(89.3)$ & $22(95.7)$ & .63 \\
\hline Family income & $\mathrm{n}=179$ & $\mathrm{n}=156$ & $\mathrm{n}=23$ & \\
\hline Low $(>\$ 50,000)$ & $57(31.8)$ & $50(32.0)$ & $7(30.4)$ & \\
\hline High $(=>\$ 50,000)$ & $122(68.2)$ & $106(67.9)$ & $16(69.6)$ & .88 \\
\hline
\end{tabular}

*Treatment patients had either surgery or radiotherapy.

tObservation patients had neither surgery nor radiotherapy.

$\ddagger$ Unless otherwise specified, statistical significance is for chi-square test (categorical variables) or independent samples $\mathrm{t}$ test (continuous variables).

§Fischer's exact test.

Table 1. Comparison of Socio-demographic Characteristics of Patients with Localized Prostate Cancer who Chose Treatment* and Observation ${ }^{\dagger}$ 
Table 2 shows a comparison of patients who chose treatment or observation by cancer grade, PSA, life expectancy by age, and co-morbidity scores. Mean Gleason grade was 6.6. Table 2 also includes a comparison of these patient groups by SF-36 scores (Physical Component and Mental Component Scores), as well as the urinary, sexual, and bowel function scores of the 144 of 184 patients who had also returned the second pretreatment survey. Table 3 shows a comparison of patients who chose treatment or observation by CALE, anxiety and depression, function capacity, social support, and satisfaction. Mean CALE was 22.9 years. Table 4 shows the baseline CALE for the 184 patients and the responses of 170 of the 184 patients who had answered questions about their perceived life expectancy without treatment (Q1) and with treatment $(\mathrm{Q} 2)$ of the cancer. Without treatment, perceived life expectancy was $<5$ years in $15.2 \%, 5$ to 10 years in $48.8 \%, 11$ to 19 years in $33.5 \%$ and 20 or more years in $2.4 \%$ of the patients. With treatment, it was $<5$ years in $0.6 \%, 5$ to 10 years in $6.5 \%, 11$ to 19 years in $30.0 \%$, and 20 or more years in $62.9 \%$ of the patients. By contrast, baseline CALE was $<5$ years in $0.5 \%$, 5 to 10 years in $2.2 \%, 11$ to 19 years in $36.4 \%$, and 20 or more years in $60.9 \%$. A total of 170 patients had data on CALE, Q1, and Q2. As compared with CALE, 65 (38.2\%) of these 170 patients expected their survival to decrease by 10 or more years without treatment. As compared with their perceived survival without treatment, $81(47.6 \%)$ of 170 patients expected their survival to increase by 10 or more years with treatment. Of the 108 patients with a baseline CALE of $>20$ years, only $2(1.9 \%)$ expected to live beyond 20 years without treatment whereas $84(77.8 \%)$ expected to live beyond 20 years with treatment (data not shown). Neither of these perceptions was significantly related to whether the patients chose treatment or observation. However, to a statistically insignificant extent, patients who chose treatment were more likely than observation patients to expect a 10 or more years reduction in survival without treatment ( $50 \%$ vs. $33.3 \%, 2$ test; $P=.26)$ and a 10 or more year increase in survival with treatment (39.9\% vs. $16.7 \%$, Fisher's exact test; $P=.13)$.

\begin{tabular}{|l|l|l|l|l|}
\hline Overall & $(\mathrm{n}[\%])$ & Treatment & Observation & \\
\hline Factors & $\mathrm{n}=184$ & $\mathrm{n}[\%])$ & $(\mathrm{n}[\%])$ & $\mathrm{P}^{*}$ \\
\hline Gleason Grade & $0(0.0)$ & $0(0.0)$ & $\mathrm{N}=23$ & \\
\hline $2-4$ & $103(55.9)$ & $84(52.1)$ & $0(0.0)$ & \\
\hline $5-6$ & $62(33.7)$ & $60(37.3)$ & $2(8.7)$ & \\
\hline 7 & $19(10.3)$ & $17(10.6)$ & $2(8.7)$ & 0.02 \\
\hline $8-10$ & $6.6+/-0.7$ & $6.6+/-0.7$ & $6.2+/-0.7$ & 0.02 \\
\hline Mean +/-SD & $\mathrm{n}=183$ & $\mathrm{n}=161$ & $\mathrm{n}=23$ & \\
\hline Prostate-specific antigen & $159(86.9)$ & $139(86.3)$ & $21(91.3)$ & \\
\hline$=<10$ & $24(13.1)$ & $22(13.7)$ & $2(8.7)$ & 0.74 \\
\hline$>\zeta 10$ & $6.7+/-5.3$ & $6.8+/-5.5$ & $5.6+/-3.4$ & 0.14 \\
\hline Mean +/-SD & $\mathrm{n}=183$ & $\mathrm{n}=160$ & $\mathrm{~N}=23$ & \\
\hline $\begin{array}{l}\text { Life expectancy by age } \\
(\text { years) }\end{array}$ & $4(2.2)$ & $2(1.3)$ & $2(8.7)$ & \\
\hline$<10$ & $104(56.8)$ & $86(53.8)$ & $18(78.3)$ & \\
\hline $10-20$ & $75(40.9)$ & $72(45.0)$ & $3(13.0)$ & $0.002^{*}$ \\
\hline$>=20$ & $\mathrm{n}=184$ & $\mathrm{n}=161$ & $\mathrm{~N}=23$ & \\
\hline Comorbidity score & & & \\
\hline
\end{tabular}




\begin{tabular}{|l|l|l|l|l|}
\hline 0 & $74(40.2)$ & $66(40.9)$ & $8(34.8)$ & \\
\hline 1 & $75(40.8)$ & $67(41.6)$ & $8(34.8)$ & \\
\hline 2 & $27(14.7)$ & $23(14.3)$ & $4(17.4)$ & \\
\hline$>=3$ & $8(4.4)$ & $5(3.1)$ & $3(13.0)$ & 0.16 \\
\hline Mean +/-SD & $0.9+/-1.0$ & $0.83+/-0.96$ & $1.26+/-1.5$ & 0.18 \\
\hline $\begin{array}{l}\text { Short Form-36 subscales } \\
\text { summary }\end{array}$ & & & & \\
\hline Mean +/-SD & $\mathrm{n}=142$ & $\mathrm{n}=134$ & $\mathrm{n}=8$ & \\
\hline $\begin{array}{l}\text { Mental component } \\
\text { summary }\end{array}$ & $54.5+/-7.6$ & $54.5+/-7.2$ & $52.6+/-12.3$ & 0.66 \\
\hline Mean+/-SD & $\mathrm{n}=142$ & $\mathrm{n}=134$ & $\mathrm{n}=8$ & \\
\hline Prostate cancer index & $44.1+/-6.8$ & $43.9+/-6.9$ & $46.4+/-4.5$ & 0.29 \\
\hline Urinary & & & & \\
\hline Mean +/-SD & $\mathrm{n}=141$ & $\mathrm{n}=132$ & $\mathrm{n}=9$ & \\
\hline Bowel & $90.2+/-16.9$ & $90.1+/-17.4$ & $91.3+/-9.3$ & 0.83 \\
\hline Mean +/-SD & $\mathrm{n}=142$ & $\mathrm{n}=133$ & $\mathrm{n}=9$ & \\
\hline Sexual & $88.8+/-12.5$ & $88.5+/-12.8$ & $92.9+/-4.5$ & 0.03 \\
\hline Mean +/- SD & $\mathrm{n}=137$ & $\mathrm{n}=128$ & $\mathrm{n}=9$ & \\
\hline Urinary Bother & $57.7+/-29.9$ & $57.8+/-30.4$ & $55.4+/-23.8$ & 0.82 \\
\hline Mean +/-SD & $\mathrm{n}=144$ & $\mathrm{n}=135$ & $\mathrm{n}=9$ & \\
\hline Bowel Bother & $86.1+/-23.0$ & $85.9+/-23.4$ & $88.9+/-18.2$ & 0.71 \\
\hline Mean +/-SD & $\mathrm{n}=144$ & $\mathrm{n}=135$ & $\mathrm{n}=9$ & \\
\hline Sexual Bother & $92.5+/-17.5$ & $92.0+/-17.9$ & $100+/-0.0$ & \} 0.0001 \\
\hline Mean +/- SD & $\mathrm{n}=142$ & $\mathrm{n}=133$ & $\mathrm{n}=9$ & \\
\hline Fear of cancer recurrence & $65.8+/-36.8$ & $65.4+/-36.8$ & $72.2+/-38.4$ & 0.59 \\
\hline Mean +/-SD & $\mathrm{n}=141$ & $\mathrm{n}=133$ & $\mathrm{n}=8$ & 0.92 \\
\hline
\end{tabular}

Table 2. Comparison of Patients who Chose Treatment and Observation by Prostate CancerRelated and Health Factors

\begin{tabular}{|l|l|l|l|l|}
\hline \multicolumn{2}{|l|}{ Overall } & Treatment & \multicolumn{2}{l|}{ Observation } \\
\hline Characteristic & & $(\mathrm{n}[\%]$ & $\left(\mathrm{n}[\%]^{* * *}\right.$ & $\mathrm{P}^{*}$ \\
\hline $\begin{array}{l}\text { Comorbidity-adjusted life } \\
\text { expectancy }\end{array}$ & & & & \\
\hline All ages & $184(100)$ & $161(100)$ & $23(100)$ & \\
\hline$<5$ years & $1(0.5)$ & $0(0)$ & $1(4.3)$ & \\
\hline $5-10$ years & $4(2.2)$ & $2(1.2)$ & $2(8.7)$ & \\
\hline $11-19$ years & $67(36.4)$ & $52(32.3)$ & $15(65.2)$ & \\
\hline$>=20$ years & $112(60.9)$ & $107(66.5)$ & $5(21.7)$ & $<.0001$ \\
\hline Mean $+/-$ SD & $22.9+/-7.6$ & $23.9+/-7.3$ & $<$ & \} .0001 \\
\hline Anxiety score & $\mathrm{n}=183$ & $\mathrm{n}=160$ & $\mathrm{n}=23$ & \\
\hline
\end{tabular}




\begin{tabular}{|c|c|c|c|c|}
\hline None/normal (0-7) & 145 (79.2) & $123(76.9)$ & $22(95.7)$ & \\
\hline Mild anxiety (8-10) & $23(12.6)$ & $23(14.4)$ & $0(0.0)$ & \\
\hline Moderate anxiety (11-14) & $12(6.6)$ & $11(6.9)$ & $1(4.4)$ & \\
\hline Clinical (15-21) & $3(1.6)$ & $3(1.9)$ & $0(0.0)$ & .18 \\
\hline Mean +/- SD & $5.1+/-3.5$ & $5.4+/-3.5$ & $2.8+/-2.9$ & .0008 \\
\hline Depression score & $\mathrm{n}=178$ & $\mathrm{n}=156$ & $\mathrm{n}=22$ & \\
\hline None/normal (0-7) & $172(96.6)$ & $150(96.2)$ & $22(100)$ & \\
\hline Mild depression (8-10) & $4(2.3)$ & $4(2.6)$ & $0(0.0)$ & \\
\hline Moderate (11-14) & $1(0.6)$ & $1(0.6)$ & $0(0.0)$ & \\
\hline Clinical (15-21) & $1(0.6)$ & $1(0.6)$ & $0(0.0)$ & .83 \\
\hline Mean +/-SD & $1.7+/-2.3$ & $1.7+/-2.4$ & $1.4+/-1.7$ & .49 \\
\hline Functional capacity & $\mathrm{n}=184$ & $\mathrm{n}=160$ & $\mathrm{n}=23$ & \\
\hline Mild activities (<3 METs) & $1(0.5)$ & $1(0.6)$ & $0(0.0)$ & \\
\hline Moderate activities (3-6 METs) & $20(10.9)$ & $15(9.3)$ & $5(21.7)$ & \\
\hline Vigorous activities (>=6 METs) & $163(88.6)$ & $145(90.1)$ & $18(78.3)$ & .19 \\
\hline Social support & $\mathrm{n}=183$ & $n=160$ & $\mathrm{n}=23$ & \\
\hline$<50$ & $7(3.8)$ & $6(3.8)$ & $1(4.4)$ & \\
\hline $50-75$ & $33(18.0)$ & $29(18.1)$ & $4(17.4)$ & \\
\hline $75-100$ & $143(78.1)$ & $125(78.1)$ & $18(78.3)$ & .98 \\
\hline Satisfaction with Life & $\mathrm{n}=178$ & $\mathrm{n}=156$ & $\mathrm{n}=22$ & \\
\hline Delighted or highly satisfied & $138(77.5)$ & $121(77.6)$ & $17(77.3)$ & \\
\hline Satisfied or lower & $40(22.5)$ & $35(22.4)$ & $5(22.7)$ & .97 \\
\hline Mean +/-SD & $6.0+/-0.9$ & $5.9+/-0.9$ & $6.1+/-1.0$ & .64 \\
\hline Satisfaction with health & $\mathrm{n}=178$ & $\mathrm{n}=156$ & $\mathrm{n}=22$ & \\
\hline Delighted or highly satisfied & $85(47.8)$ & $72(46.1)$ & $13(59.1)$ & \\
\hline Satisfied or lower & $93(52.3)$ & $84(53.9)$ & $9(40.9)$ & .26 \\
\hline Mean +/- SD & $5.0+/-1.3$ & $5.0+/-1.3$ & $5.4+/-1.4$ & .19 \\
\hline $\begin{array}{l}\text { Satisfaction with education by } \\
\text { physician in treatment choices }\end{array}$ & $\mathrm{n}=178$ & $\mathrm{n}=156$ & $\mathrm{n}=22$ & \\
\hline Delighted or highly satisfied & $141(79.2)$ & $126(80.8)$ & $15(68.2)$ & \\
\hline Satisfied or lower & $37(20.8)$ & $30(19.2)$ & $7(31.8)$ & .17 \\
\hline Mean +/- SD & $6.1+/-0.9$ & $6.1+/-0.9$ & $5.9+/-1.1$ & .1 \\
\hline
\end{tabular}

*Treatment patients had either surgery or radiotherapy.

†Observation patients had neither surgery nor radiotherapy.

$\ddagger$ Unless otherwise specified, statistical significance is for chi-square test (categorical variables) or independent samples $t$ test (continuous variables).

MET, metabolic equivalent.

Table 3. Distribution of Men by Prostate Cancer-Related and Health Characteristics 


\begin{tabular}{|l|c|c|r|}
\hline \multirow{2}{*}{$\begin{array}{l}\text { Expected Survival } \\
\text { years })\end{array}$} & Baseline CALE Score & Q1 & Q2 \\
\cline { 2 - 4 } & $(\mathrm{n}=184)$ & $(\mathrm{n}=170)$ & $(\mathrm{n}=170)$ \\
\hline$<5$ & $1(0.5)$ & $26(15.2)$ & $1(0.6)$ \\
\hline $5-10$ & $4(2.2)$ & $83(48.8)$ & $11(6.5)$ \\
\hline $11-19$ & $67(36.4)$ & $57(33.5)$ & $51(30.0)$ \\
\hline$>=20$ & $112(60.9)$ & $4(2.4)$ & $107(62.9)$ \\
\hline
\end{tabular}

Data provided as $\mathrm{n}(\%)$.

CALE, co-morbidity adjusted life expectancy; Q1, How long do you expect you will live without any treatment for prostate cancer?; Q2, How long do you expect you will live after the treatment of your choice for prostate cancer?

Table 4. Distribution of Men with Localized Prostate Cancer by Calculated Co-morbidity Adjusted Life Expectancy

Tables 5 and 6 present ordinal logistic regression models for PDLO and PILT. Age, CALE, depression, and anxiety scores predicted both PDLO and PILT. Furthermore, PSA level predicted PDLO, whereas social support predicted PILT.

\begin{tabular}{|c|c|c|c|c|c|}
\hline & \multicolumn{4}{|c|}{ Unadjusted Effects } & \multirow{2}{*}{$\begin{array}{c}\text { Adjusted Effects (OR } \\
95 \% \text { CI) }\end{array}$} \\
\hline & $\begin{array}{c}\text { PDLO } \\
=<0^{*}\end{array}$ & PDLO = $1^{\dagger}$ & $\begin{array}{c}\text { PDLO } \\
=>2^{\ddagger}\end{array}$ & OR (95\% CI) & $1.01(0.92-1.10)$ \\
\hline Age & 25 & 62 & 83 & $1.08(1.04-1.13)$ & $0.93(0.86-1.00)$ \\
\hline PSA level & 25 & 62 & 82 & $0.94(0.88-1.00)$ & $0.93(0.84-1.02)$ \\
\hline CALE & 25 & 62 & 83 & $0.92(0.88-0.96)$ & $0.96(0.85-1.08)$ \\
\hline Anxiety score & 25 & 62 & 83 & $0.88(0.81-0.96)$ & $0.85(0.69-1.04)$ \\
\hline Depression score & 25 & 58 & 82 & $0.79(0.67-0.93)$ & 0.85 \\
\hline
\end{tabular}

${ }^{*} \mathrm{~A}(\mathrm{PDLO})=<0$ (reference group) indicates that CALE and self-reported survival expectation without treatment are within the same range or CALE is less.

$\dagger \mathrm{A}(\mathrm{PDLO})=1$ suggests that CALE exceeds self-reported survival expectation without treatment by one response category.

$\ddagger \mathrm{A}(\mathrm{PDLO})>=2$ suggests that CALE exceeds self-reported survival expectation without treatment by at least 2 response categories (ie.,

about 10 years). All covariates in the ordinal logistic regression model are defined as continuous variables.

PDLO, perceived decrease in longevity with observation (categorized); PSA, prostate-specific antigen;

CALE, comorbidity adjusted life expectancy; OR, odds ratio.

Table 5. Ordinal Logistic Regression Modeling for Perceived Decrease in Longevity with Observation (PDLO) among Men with Localized Prostate Cancer 


\begin{tabular}{|c|c|c|c|c|c|}
\hline & \multicolumn{4}{|c|}{ Unadjusted Effects } & \multirow{2}{*}{$\begin{array}{c}\text { Adjusted Effects (OR } \\
95 \% \text { CI) }\end{array}$} \\
\hline PILT $=<0^{*}$ & PILT $=1^{\dagger}$ & $\begin{array}{c}\text { PILT } \\
=>2^{\ddagger}\end{array}$ & OR (95\% CI) & $1.09(0.99-1.19)$ \\
\hline Age & 18 & 87 & 65 & $1.08(1.04-1.13)$ & $1.02(0.93-1.12)$ \\
\hline CALE & 18 & 87 & 65 & $0.93(0.89-0.97)$ & $0.91(0.81-1.02)$ \\
\hline Anxiety Score & 18 & 87 & 65 & $0.89(0.82-0.98)$ & $1.06(0.89-1.26)$ \\
\hline Depression score & 18 & 83 & 64 & $0.93(0.82-1.05)$ & $1.00(0.98-1.02)$ \\
\hline
\end{tabular}

*PILT <=0 (reference group) indicates that CALE and self-reported survival expectation with treatment are within the same range or CALE is less.

†A $($ PILT $)=1$ suggests that CALE exceeds self-reported survival expectation with treatment by one response category.

$\ddagger A$ (PILT) >=2 suggests that CALE exceeds self-reported survival expectation with treatment by at least 2 response categories (ie.,

about 10 years). All covariates in the ordinal logistic regression model are defined as continuous variables.

PILT, perceived increase in longevity with treatment (categorized); CALE, comorbidity adjusted life expectancy; OR, odds ratio.

Table 6. Ordinal Logistic Regression Modeling for Perceived Increase in Longevity with Treatment (PILT) among Men with Localized Prostate Cancer

\section{Discussion}

Prostate cancer is the most common solid cancer in men. Younger patients make up a fast growing population that is being screen-detected and treated for low-risk LPC. ${ }^{25}$ To our knowledge, this is the first study to report the perceptions of newly diagnosed patients about how the cancer or its treatment could affect their survival. The mean age of our patients (61.5 years) was similar to the range of 58 to 64 years of US patients currently undergoing radical prostatectomy.26 The mean Gleason grade was 6.6 in our patients, similar to other series in which almost half of screen-detected cancers were "insignificant." 27 By choosing treatment, these low-risk patients had accepted the treatment side effects in exchange for longer anticipated survival. Our questions were designed to find how much longer these patients expected to live by choosing treatment. These expectations were evaluated after the patients had discussed their treatment options with their urologists. Despite their mean baseline CALE of 22.9 years, without treatment, 26 of 170 patients expected to live $<5$ years and only 4 expected to live $>20$ years; with treatment, only 1 expected to live $<5$ years and 107 patients expected to live $>20$ years.

What should these patients really be expecting? Nearly $86 \%$ of all patients diagnosed through PSA screening are not expected to die because of prostate cancer. ${ }^{28}$ The Connecticut Tumor Registry found that almost $20 \%$ of patients with Gleason grade 6 or higher who chose observation died as a result of LPC during a period of 20 years. ${ }^{29}$ However, all the Registry's patients had been clinically diagnosed; in contrast, patients diagnosed with screen-detected LPC are expected to have a longer survival because of a gain in lead time. Patients in another commonly cited natural history study ${ }^{30}$ were also not diagnosed by PSA screening. A review ${ }^{31}$ found that only one randomized, high-quality trial ${ }^{32}$ could find a 
survival benefit of treatment, but in this trial $95 \%$ of patients had cancer that was clinically palpable (and not detected by PSA screening), putting this cohort in an intermediate- to high-risk category. A study of 44,630 men found a survival benefit of treatment, 33 but only $2.1 \%$ of the patient sample had died of prostate cancer. If adjusted for lead time provided by screening and also for the impairment of HRQOL that follows treatment, treatment was projected to enhance quality-adjusted survival by only 0.5 year. ${ }^{34}$

Overtreatment would be expected if patients believe that treatment will lead to a much longer survival. Many studies have found that nearly every patient initially wants eradication of the cancer. ${ }^{9}$ In qualitative studies, some patients accepted side effects for any gain in survival but they were convinced that treatment would improve survival. ${ }^{9}$ Assuming that tumors would grow exponentially, urologists at the Mayo Clinic were also of the opinion that only $0.3 \%$ and $14.5 \%$ of screen-detected LPCs were "clinically insignificant." 35 Patient anxiety caused by the new diagnosis of cancer and the consensus advice of specialists that LPC patients with a CALE of $>10$ years should choose treatment or be offered treatment6 will lead to high treatment rates. In $70 \%$ to $90 \%$ of patients, a treatment plan is usually made in a single visit to the urologist after a positive biopsy. ${ }^{36}$ The mean Gleason grade of our patients was 6.6 , and in $87 \%$ of patients the mean PSA was $<10$, both of which are low-risk categories but for which national guidelines recommend either observation or treatment. ${ }^{8}$ Only $12.5 \%$ of patients in our study chose observation. Specialists frequently recommend treatment even in low-risk patients because over 10 to 15 years the cancer may progress. ${ }^{29}$ To manage this risk, a strategy of active surveillance with deferred initial treatment ${ }^{28}$ is being increasingly recommended for patients at lower risk, ie, with cancers of Gleason grade $<7$, cancer stages T1c to T2a, and PSA $<10$. Almost half of patients with screen-detected cancer possess such characteristics. ${ }^{27}$ In conjunction with specialists, primary care physicians (PCPs) can follow patients who choose this strategy. PCPs may also offer more balanced advice because they might be more knowledgeable about the patient's preferences, co-morbidities, and baseline CALE. ${ }^{37}$ Patients with LPC may also want to review educational materials with their PCP. The American Cancer Society website was recommended because its content, accuracy, balance, and readability was rated the highest among 44 patient education materials about LPC. 38

Overtreatment can also be reduced with decreased screening, and several studies have shown that fewer patients want PSA screening if they are counseled before screening. ${ }^{39}$ Enthusiasm for routine screening is high among specialists who treat LPC. In a random nationwide survey, $43 \%$ of 559 radiation oncologists recommended routine PSA screening in average-risk patients older than 80.6 Primary care physicians who frequently order PSA testing without much discussion about risks and benefits of testing cited reasons of lack of time, competing demands, limited patient health literacy, and fear of liability. ${ }^{40}$ Prescreening counseling is difficult because it is unclear what and how much discussion should occur. As yet, we cannot say that screening or treatment can improve survival. The deleterious effects of treatment on urinary, bowel, and sexual dysfunction are better known; however, their frequencies and severities after different treatment techniques have been reported in more than 800 publications, ${ }^{41}$ vary greatly, and are difficult to balance. We can also share with patients that there is a small risk of immediate morbidity and mortality associated with prostate biopsy and cancer treatment; that a new anxiety results from a positive PSA test, whether or not it is followed by a negative biopsy; and that we cannot compare the risk of death caused by co-morbid diseases with that of death caused by cancer without knowing the grade and stage of the cancer. However, patients must also know that, even if diagnosed 
with cancer, no randomized controlled trial has shown that treatment can or cannot improve survival in patients with screen-detected cancer. Interestingly, a study found that more African American patients wanted PSA screening after the use of a decision aid, 39 presumably because of the appreciation of the higher risk in African American patients.

In our patients, age, CALE, depression, and anxiety were the most important predictors of PDLO or PILT. Though PSA level also influenced PDLO, PILT was related to social support. PDLO and PILT were not related to other factors such as race; income; education; health literacy; physical and mental summary SF-36 scores; urinary, bowel, and sexual symptoms; choice of treatment or observation; fear of cancer recurrence; functional capacity; and satisfaction with life, health, or with education by physicians in cancer treatment options. Although the association of PDLO and PILT with continuous depression scores was statistically significant, the importance of this finding is unclear given that $96.6 \%$ patients had a depression score of $<7$, which indicates no depression.

Our findings may be difficult to generalize because our study sample was small. However, the differences we found between CALE and patient expectations of survival with and without treatment were large. Also, the mean age ${ }^{26}$ and mean cancer grade ${ }^{27}$ of patients newly diagnosed with LPC in large series and in our patients were similar. Our patients were treated by urologists in a private practice and more than $80 \%$ of urologists in the United States are in private practice. ${ }^{42}$ Our method of equating CCI scores with NCCN recommended health quartiles to estimate CALE is new and has not been previously validated. We used this method because we could not find any other validated method to estimate long-term health-adjusted life expectancy in individual ambulatory patients. Finally, we lost accuracy in the estimation of PDLO and PILT by asking patients to predict their survival in ordinal intervals rather than in a discrete number of years. We used ordinal intervals because it might be easier for patients to predict their survival this way, and the intervals allowed an estimation of PDLO and PILT of more than or less than 10 years. We have also published these findings earlier. ${ }^{43}$

We had also studied whether our patients had adequate Knowledge, Understanding and Judgment (KUJ) of their treatment options by using a KUJ 18-item questionnaire that we have developed; we found that although the vast majority of our patients were educated, had good health literacy and had higher income, over half of the patients incorrectly answered over half of the questions on the KUJ scale. These findings have been published separately. ${ }^{44}$ Additionally, we had studied whether our patients had chosen treatment or observation in accordance with current NCCN guidelines and we had found that a majority had chosen over-treatment, i.e., they had chosen treatment even though for their clinical situation the NCCN had recommended observation as an equal alternative. These findings were published recently, 45 and had demonstrated that with the use of our method to estimate CALE it becomes feasible to use NCCN guidelines in decision-making in individual patients. Based on our research and NCCN guidelines, in August 2011 we have published a comprehensive and easy-to-understand approach in the journal American Family Physician (AFP) ${ }^{46}$ which can be used by newly-diagnosed patients and their physicians in quickly reaching an evidence-based and guideline-driven treatment choice. Decisionmaking is very hard especially for low-risk patients, traditionally primary care physicians are not involved in this process, and over $70 \%$ to $80 \%$ patients choose a treatment or observation in the first visit to the urologist after a positive biopsy. Although newer guidelines now recommend against PSA screening, ${ }^{47}$ this recommendation carries the risk of increasing mortality due to prostate cancer and prostate cancer is already the second most 
common cause of cancer death in American men. The algorithm and tools provided in our publication in AFP can empower primary care physicians in counseling newly-diagnosed patients and reduce the risk of over-treatment by convincing low-risk patients to choose active surveillance. With this safeguard, patients and physicians can choose screening for prostate cancer with less hesitation.

\section{Conclusion}

In patients with newly diagnosed LPC, in whom the mean cancer grade was $<7$ and in whom education, income, and health literacy was intermediate to high, almost $38 \%$ of our patients had expectations of a reduction in survival of 10 or more years if they chose observation, and $48.8 \%$ patients expected an improvement in survival of 10 or more years through choosing treatment. These expectations are highly unrealistic because no study has shown that the cancer or its treatment can affect survival by even 1 year, especially in screen-detected patients with a cancer Gleason grade of $<7$.

\section{Acknowledgements}

This article has been reproduced by permission of the American Board of Family Medicine. We thank Mr. Brian Main, Department of Urology, Eastern Virginia Medical School, for help with data entry and analysis.

\section{References}

[1] Taichman RS, Loberg RD, Mehra R, Pienta KJ. The evolving biology and treatment of prostate cancer. J Clin Invest 2007;117:2351-61.

[2] Etzioni R, Penson D, Legler JM, et al. Overdiagnosis due to prostate-specific antigen screening: lessons from US prostate cancer incidence trends. J Natl Cancer Inst 2002;94:981-90.

[3] Miller DC, Gruber SB, Hollenbeck BK, Montie JE, Wei JT. Incidence of initial local therapy among men with lower-risk prostate cancer in the United States. J Natl Cancer Inst 2006;98:1134-41.

[4] Harlan SR, Cooperberg MR, Elkin EP, et al. Time trends and characteristics of men choosing watchful waiting for initial treatment of localized prostate cancer: results from CaPSURE. J Urol 2003;170:1804-7.

[5] Parker C, Muston D, Melia J, Moss S, Dearnely D. A model of the natural history of screen-detected prostate cancer, and the effect of radical treatment on overall survival. Br J Cancer 2006;94:1361- 8.

[6] Fowler FJ, Collins MM, Albertsen PC, Zeitman A, Elliott DB, Barry MJ. Comparison of recommendations by urologists and radiation oncologists for treatment of localized prostate cancer. JAMA 2000; 283:3217.

[7] Krahn MD, Bremner KE, Asaria J, et al. The ten year rule revisited: accuracy of clinicians' estimates of life expectancy in patients with localized prostate cancer. Urology 2002;60:258-63.

[8] National Comprehensive Cancer Network. NCCN Clinical Practice Guidelines in Oncology: prostate cancer. Available from

http://www.nccn.org/professionals/physician_gls/PDF/prostate.pdf. Accessed, 25 January 2009. 
[9] Zeliadt SB, Ramsey SD, Penson DF, et al. Why do men choose one treatment over another? A review of patient decision making for localized prostate cancer. Cancer 2006;106:1865-74.

[10] Miller DC, Sanda MG, Dunn RL, et al. Long-term outcomes among localized prostate cancer survivors: health-related quality-of-life changes after radical prostatectomy, external radiation, and brachytherapy. J Clin Oncol 2005;23:2772- 80.

[11] Hu JC, Kwan L, Saigal CS, Litwin MS. Regret in men treated for localized prostate cancer. J Urol 2003;169:2279-83.

[12] Walz J, Gallina A, Saad F, et al. A nomogram predicting 10-year life expectancy in candidates for radical prostatectomy or radiotherapy for prostate cancer. J Clin Oncol 2007;25:3576-81.

[13] Wilson JRM, Clarke MG, Ewings P, Graham JD, MacDonagh R. The assessment of patient life expectancy: how accurate are urologists and oncologists? BJU Int 2005;95:794-8.

[14] Bass PF, Wilson JF, Griffith CH. A shortened instrument for literacy screening. J Gen Intern Med 2003;18:1036-8.

[15] Hoffman RM, Stone SM, Espey D, Potosky A. Differences between men with screeningdetected versus clinically diagnosed prostate cancers in the USA. BMC Cancer 2005;5:27.

[16] Walter LC, Covinsky KE. Cancer screening in elderly patients: a framework for individualized decision making. JAMA 2001;285:2750-6.

[17] Post PN, Hansen BE, Kil PJM, Coebergh JWW. The independent prognostic value of comorbidity among men aged _ 75 years with localized prostate cancer: a population-based study. BJU Int 2001;87:821-6.

[18] Ware JE, Kosinki M. SF-36 Physical and Mental Health Summary Scales: a manual for users of version 1, 2nd ed. Lincoln (RI): QualityMetric, Inc.; 2005.

[19] Litwin M, Hays RD, Fink A, Ganz PA, Leake B, Brooke RH. The UCLA Prostate Cancer Index: development, reliability, and validity of a health-related quality of life measure. Med Care 1998;36:1002-12.

[20] Hlatky MA, Boineau RE, Higginbotham MB, et al. A brief self-administered questionnaire to determine functional capacity (The Duke Activity Status Index). Am J Cardiol 1989;64:651- 4.

[21] Zigmond AS, Snaith RP. The Hospital Anxiety and Depression scale. Acta Psychiatr Scand 1983;67:361-70.

[22] Mehta SS, Lubeck DP, Pasta DJ, Litwin M. Fear of cancer recurrence in patients undergoing definitive treatment for prostate cancer: results from CaPSURE. J Urol 2003;170:1931-3.

[23] Sherbourne CD, Stewart AL. The MOS Social Support Survey. Soc Sci Med 1991;32:705-14.

[24] Bowling A. Measuring health: a review of quality of life measurement scales, 2nd ed. Buckingham (UK): Open University Press; 1997.

[25] Cooperberg MR, Lubeck DP, Meng MV, Mehta SS, Caroll PR. The changing face of lowrisk prostate cancer: trends in clinical presentation and primary management. J Clin Oncol 2004;22:2141-9.

[26] Jang TL, Yossepowitch O, Bianco FJ, Scardino PT. Low risk prostate cancer in men under age 65: the case for definitive treatment. Urol Oncol 2007;25: 510-4.

[27] Draisma G, Boer R, Otto SJ, et al. Lead times and over detection due to prostate-specific antigen screening: estimates from the European Randomized Study of Screening for Prostate Cancer. J Natl Cancer Inst 2003;95:868 -78.

[28] Klotz L. Active surveillance for prostate cancer: for whom? J Clin Oncol 2005;23:8165-9.

[29] Albertsen PC, Hanley JA, Fine J. 20-year outcomes following conservative management of clinically localized prostate cancer. JAMA 2005;293:2095-101. 
[30] Johansson JE, Andren O, Andersson SO, et al. Natural history of early, localized prostate cancer. JAMA 2004;291:2713-9.

[31] Alibhai SM, Klotz LH. A systematic review of randomized trials in localized prostate cancer. Can J Urol 2004;11:2110 -7.

[32] Bill-Axelson A, Holmberg L, Ruutu M, et al. Radical prostatectomy versus watchful waiting in early prostate cancer. N Engl J Med 2005;352:1977-84.

[33] Wong YN, Mitra N, Hudes G, et al. Survival associated with treatment vs observation of localized prostate cancer in elderly men. JAMA 2006;296: 2683-93.

[34] Bhatnagar V, Stewart ST, Bonney WW, Kaplan RM. Treatment options for localized prostate cancer: quality-adjusted life years and the effects of leadtime. Urology 2004;63:103-9.

[35] Dugan JA, Bostwick DG, Myers RP, Qian J, Bregstralh EJ, Oesterling JE. The definition and preoperative prediction of clinically insignificant prostate cancer. JAMA 1996;275:288 -94.

[36] Cohen H, Britten N. Who decides about prostate cancer treatment? A qualitative study. Fam Pract 2003;20:724 -9.

[37] Mohan R. Family physicians could help in predicting life expectancy without prostate cancer. J Clin Oncol 2008;26:690 -1.

[38] Fagerlin A, Rovner D, Stableford S, Jentoft C, Wei JT, Holmes-Rovner M. Patient education materials about the treatment of early stage prostate cancer: a critical review. Ann Intern Med 2004;140:721- 8.

[39] Volk RJ, Hawley ST, Kneuper S, et al. Trials of decision aids for prostate cancer screening: a systematic review. Am J Prev Med 2007;33:428 -34.

[40] Guerra CE, Jacobs SE, Holmes JH, Shea JA. Are physicians discussing prostate cancer screening with their patients and why or why not? A pilot study. J Gen Intern Med 2007;22:901-7.

[41] Visser A, van Andel G. Psychosocial and educational aspects in prostate cancer patients. Patient Educ Couns 2003;49:203- 6.

[42] American Urological Association. Member profile. October 2008. Available from http://www.auanet.org/content/about-us/members/membersprofile. pdf. Accessed 28 January 2009.

[43] Mohan R, Beydoun H, Barnes-Ely ML, Lee L, Davis JW, Lance R, Schellhammer P. Patients' survival expectations before localized prostate cancer treatment by treatment status. J Am Board Fam Med. 2009 May-Jun;22(3):247-56.

[44] Beydoun HA, Mohan R, Beydoun MA, Davis J, Lance R, Schellhammer P. Development of a scale to assess patient misperceptions about treatment choices for localized prostate cancer. British Journal of Urology International, 2010 Feb 11. [Epub ahead of print]. Available at: http:/ / www3.interscience.wiley.com/cgi-bin/fulltext/123280002/PDFSTART

[45] Mohan R, Beydoun H, Davis J, Lance R, Schellhammer P. Feasibility of using guidelines to choose treatment for prostate cancer. Can J Urol. 17:4975-84, 2010. Abstract available at: http://www.ncbi.nlm.nih.gov/pubmed/20156376

[46] Mohan R, Schellhammer P. Treatment options in Localized Prostate Cancer. American Family Physician, August 15th, 2011. 84(4):413-20.

[47] Chou R, Croswell JM, Dana T, Bougatsos C, Blazina I, Fu R, Gleitsmann K, Koenig HC, Lam C, Maltz A, Rugge JB, Lin K.Screening for Prostate Cancer: A Review of the Evidence for the U.S. Preventive Services Task Force. Ann Intern Med. 2011 Oct 7. [Epub ahead of print] 


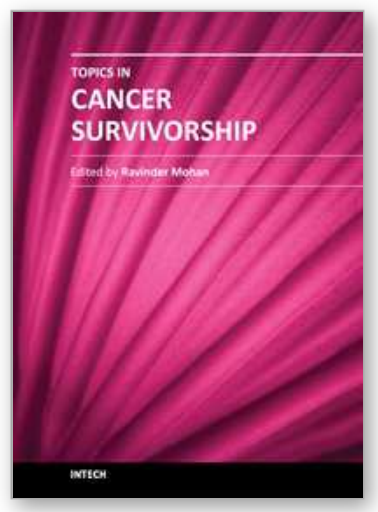

\author{
Topics in Cancer Survivorship \\ Edited by Prof. Ravinder Mohan
}

ISBN 978-953-307-894-6

Hard cover, 290 pages

Publisher InTech

Published online 27, January, 2012

Published in print edition January, 2012

Cancer is now the leading cause of death in the world. In the U.S., one in two men and one in three women will be diagnosed with a non-skin cancer in their lifetime. Cancer patients are living longer than ever before. For instance, when detected early, the five-year survival for breast cancer is $98 \%$, and it is about $84 \%$ in patients with regional disease. However, the diagnosis and treatment of cancer is very distressing. Cancer patients frequently suffer from pain, disfigurement, depression, fatigue, physical dysfunctions, frequent visits to doctors and hospitals, multiple tests and procedures with the possibility of treatment complications, and the financial impact of the diagnosis on their life. This book presents a number of ways that can help cancer patients to look, feel and become healthier, take care of specific symptoms such as hair loss, arm swelling, and shortness of breath, and improve their intimacy, sexuality, and fertility.

\title{
How to reference
}

In order to correctly reference this scholarly work, feel free to copy and paste the following:

Ravinder Mohan, Hind Beydoun, Myra L. Barnes-Ely, LaShonda Lee, John W. Davis, Raymond Lance and Paul Schellhammer (2012). Patients' Survival Expectations Before Localized Prostate Cancer Treatment by Treatment Status, Topics in Cancer Survivorship, Prof. Ravinder Mohan (Ed.), ISBN: 978-953-307-894-6, InTech, Available from: http://www.intechopen.com/books/topics-in-cancer-survivorship/patients-survivalexpectations-before-localized-prostate-cancer-treatment-by-treatment-status

\section{INTECH}

open science | open minds

\section{InTech Europe}

University Campus STeP Ri

Slavka Krautzeka 83/A

51000 Rijeka, Croatia

Phone: +385 (51) 770447

Fax: +385 (51) 686166

www.intechopen.com

\section{InTech China}

Unit 405, Office Block, Hotel Equatorial Shanghai

No.65, Yan An Road (West), Shanghai, 200040, China 中国上海市延安西路65号上海国际贵都大饭店办公楼 405 单元 Phone: +86-21-62489820

Fax: $+86-21-62489821$ 
(C) 2012 The Author(s). Licensee IntechOpen. This is an open access article distributed under the terms of the Creative Commons Attribution 3.0 License, which permits unrestricted use, distribution, and reproduction in any medium, provided the original work is properly cited. 